\title{
Power-law productivity and positive regime shift of symbiotic and climate-resilient edible ecosystems
}

Masatoshi Funabashi ( $\square$ masa_funabashi@csl.sony.co.jp )

Sony Computer Science Laboratories, Inc.

Article

Keywords: Primary Food Production, Biodiversity Loss, Low-input Mixed Polyculture, Synecoculture

Posted Date: December 15th, 2020

DOI: https://doi.org/10.21203/rs.3.rs-80005/v1

License: (c) (i) This work is licensed under a Creative Commons Attribution 4.0 International License. Read Full License 
Title: Power-law productivity and positive regime shift of symbiotic and climate-resilient edible ecosystems

\author{
Sony Computer Science Laboratories, Inc. Tokyo, Japan \\ masa_funabashi@csl.sony.co.jp \\ Masatoshi Funabashi
}

\title{
-Article summary
}

Transformative change in primary food production is urgently needed in the face of climate change and biodiversity loss. Although there are a growing number of studies aimed at global policymaking, actual implementations require on-site deep analyses of social-ecological feasibility. Here, we report the first implementations of low-input mixed polyculture of highly diverse crops (synecoculture) in Japan and Burkina Faso. Results showed that the selforganized primary production of ecosystems follows a power law and performs better compared with conventional monoculture methods in 1) promoting diversity and total quantity of products along with rapid increase of in-field biodiversity, especially in a semiarid environment where local reversal of regime shift is observed; 2) a fundamental reduction of inputs and environmental load; and 3) ecosystem-based autonomous adaptation of the crop portfolio to climatic variability. The overall benefits imply substantial possibilities for a new typology of sustainable farming based on human-guided augmentation of ecosystem services and biodiversity maintenance mechanisms that could overcome the historical trade-off between productivity and biodiversity.

\section{-100-word summary for scientists}

The power-law distribution of the spatial self-organization of vegetation facilitated by symbiotic interactions in natural ecosystems has been studied in the field of community ecology. On the other hand, innovations in crop production have traditionally been driven by optimization of monoculture, but have caused massive disruption of environmental material cycles and biodiversity. This study provides the first evidence that such trade-offs between productivity and biodiversity can be resolved by establishing communities of hundreds of crop species based on the self-organization process inherent in natural ecosystems and by adapting the management modalities to enhance productivity and resilience without external inputs of fertilizers and agrochemicals.

\section{-100-word summary for general public}

Agriculture has been degrading environments since the dawn of civilization. Natural ecosystems, on the other hand, have a lush complexity that fortify their species for survival through evolution. This study provides the first evidence that crop production based on the natural organization of highly biodiverse ecosystems can overcome the trade-off between crop productivity and environmental load: Synecoculture, which is based on the strategic association of hundreds of edible plants without the need for fertilizers or agrochemicals, shows high productivity and intrinsic adaptation to fluctuating environments and can be utilized as a remedy against imminent desertification. 


\section{Introduction}

Many studies have sounded alerts about global ecological deterioration due to the accelerating impacts of human activity in the last century (e.g., ref. 1-4). The $6^{\text {th }}$ mass extinction is underway in a wide range of biotic communities, including primary forests $^{5}$, vertebrates ${ }^{6}$, and insect fauna ${ }^{7}$.

These impacts are largely due to the primary food production on land and have caused critical environmental shifts in marine ecosystems ${ }^{8}$ : Here, the agricultural sector is responsible for $25 \%$ of greenhouse gases $(\mathrm{GHGs})^{9}$, and it has disrupted global biochemical flows and biosphere integrity ${ }^{10}$. However, interactive responses to changes in human activities, material cycles, and biodiversity distribution, including effects induced by climate change mitigation and conservation activities, are extremely complex and difficult to simulate. Globally assessed scenarios (e.g., ref. 4, 11) are not capable of predicting actual social emergencies, such as the COVID-19 pandemic, and cannot promptly address the root causes. Moreover, the importance of an integrated approach to the science of climate and biodiversity changes and the development of coherent policies has only recently been realized (e.g., ref. 12). Current economic theory and practice do not sufficiently incorporate a valuation of biodiversity and multiple ecosystem services ${ }^{13}$; we need to take comprehensive measures interconnecting direct drivers of ecosystem deterioration and underlying economic, social, and technological causes, in order to regenerate the ecologically driven material cycles and substantially reducing agricultural inputs and runoff ${ }^{3,14}$.

Many global-scale simulations have suggested possible scenarios toward sustainable land use aimed at recovery of biodiversity and the carbon cycle (e.g. ref. 15, 16). On the other hand, despite their scale, these studies are based on databases that do not necessarily encompass the whole socialecological complexity required for an actual implementation. The interactions of many parameters and the complexity of community dynamics have largely been ignored (e.g., in a food-system change scenario ${ }^{15}$, the cross-field phosphorus cycle ${ }^{17}$ and management breakthrough on the carbon cycle ${ }^{18}$ are not included; in a global afforestation scenario ${ }^{16}$, the implausibility of afforestation of naturally maintained grasslands and savannas and thermodynamic trade-off between tree cover increase and consequent diminishment of albedo ${ }^{19}$ are not considered), and deep case studies are needed in connection to a realistic driving force. The ground truth is often ignored even in basic statistical studies; this makes the applicability of global scenarios to actual situations quite elusive- while $84 \%$ of farms are owned by smallholders producing on less than 2 ha, estimates of the total surface of smallholds vary from $12 \%$ to $40 \%$ of the global farmland depending on the method of measurement ${ }^{20}$.

In order to convert the majority of food producers (especially resource-, knowledge-, and technology-deprived smallholders) into positive drivers of biodiversity, on-site tailoring and proactive management of agrobiodiversity in a comprehensive social-ecological context are important leverage points ${ }^{3,21}$. An essential pillar of transformative change in food production is to deliver a managementintensive typology of sustainable practices that contains interfaces with the diversity and uniqueness of real-world operations on a scientific basis, which has been studied 
in the field of open complex systems science ${ }^{14,22,23}$. We need complementarity between a general theory based on averaged statistics and deep analyses of individual cases in order to make progress toward the inclusion of neglected diversity. With the rise of big data, such a paradigm has emerged in the management of living systems, such as in precision medicine (e.g., N-of-1 studies ${ }^{24}$ and longitudinal deep phenotyping ${ }^{25}$ ). This study aims to provide the pioneering cases of such a paradigm for planetary health with the basis of community ecology perspective, towards the application to the grassroot majority of world food production.

\section{Crop production at ecological optimum}

Empirical studies in ecology have revealed the positive contribution of species diversity and the symbiotic relationship between plants to the primary production of ecosystems at the community level (e.g., ref. 26), especially in relation with surface patterns that follow power-law distribution ${ }^{27,28}$. Although knowledge of selforganized natural vegetation constitutes a better understanding of community dynamics and has been used for planning conservation practices, little of it has been applied to crop production.

Synecological farming (synecoculture) takes advantage of the sustainable productivity of self-organized vegetation that occurs when there is an extremely high diversity of crops ${ }^{14,29,30}$. The principle of production in synecoculture is fundamentally different from those of other low-input organic and natural farming methods that are limited in their association and rotation of a few crops (e.g., ref. 31). In contrast to the conventional definition of productivity based on a single crop and a field environment controlled toward its physiological optimum, synecoculture relies on the primary production of a mixed community that comprises tens to hundreds of edible plant species; this sort of production is known as augmentation of the ecological optimum (explained in Box 1).

\section{Symbiosis-dominant ecosystems with crops}

To evaluate the self-organization process of a mixed community of crops, a 420 -sq.m plot in the temperate zone (Oiso, Japan) was used to measure the species-wise surface at the early stage of synecoculture introduction (Fig 2 (a1-a4)). The inverse cumulative distribution of the species diversity on the surface was closer to a power-law distribution than an exponential distribution, implying that the symbiotic interactions between plants are inherent besides the competition for resources (Fig 3 (a), see Methods).

The probability density of the species-wise surface in each 2-sq.m measurement section also followed a power law (Figure 5 (top) of the Extended Data). The relative degree of symbiotic relationship can be compared with the parameter $\lambda$ and showed that naturally occurring spontaneous species (usually considered to be weeds) form vegetation patterns that contain more positive interactions ( $\lambda$ closer to zero) than the introduced crop species. This tendency was also observed in another classification of edible and non-edible plants based on past usage in synecoculture practices. Positive diversity responses to climate variability were also dominant in spontaneous species (see Fig 2 of Extended Data). The direct implication is that the coexistence of naturally occurring non-edible species serves as a substantial source of 
symbiotic gain for the whole community dynamics that promotes ecological succession, and it may contribute to the productivity of crops and other edible plants through an overall increase in resources such as soil organic matter and soil microbial activity $^{32}$.

\section{Production experiments}

The productivity of synecoculture in temperate and semi-arid tropical zones was tested in two farms, on a 1,000 sq.m farm in Ise, Japan over the course of four years (Fig 2 (b1-b2)) and on a 500 sq.m farm in Mahadaga, Burkina Faso over the course of three years (Fig 2 (c1-c5)). The probability density of product-sales data based on asynchronous thinning of highly diverse mixed polyculture showed a long-tail distribution that largely deviated from a conventional normal distribution (Fig 4 (a, b) and Fig $5(\mathrm{a}, \mathrm{b})$ ), and it followed power law (See Figure 5 (middle and bottom) of the Extended Data, and examples of harvests in Fig 2 (b2) of the main text), regardless of the differences in climate region and species composition.

Despite the no-input practice except water and introduction of seeds and seedlings, on-site observation implied overall and multiple increases in ecosystem functions along with the ecological succession in the fields, such as improvement in crop yield, the establishment of a complex food chain that supported ecological regulation of pests, thick development of porous soil structure, increased humus and soil organic matter, improved water retention and permeability, and the resulting activation of soil microbiota (see e.g., Fig 2 (c4-c5), Figure 6 (a1) and (b1) of the Extended Data, and ref. 23, 29, 33).

The average profitability (measured as gross profit minus costs) of synecoculture in the Ise farm rose 2.35- to 3.87-fold, which corresponds to an estimated 0.981- to 1.16-fold increase in harvest biomass, compared with the conventional databases of all scales and small scale $(<0.5 \mathrm{ha})$ (see the description of the relative biomass ratio BR in Methods). Compared with the median (and $25^{\text {th }}$ and $75^{\text {th }}$ percentiles) of conventional market gardening, the profitability of synecoculture in the Mahadaga farm rose 88.0(202/54.4)-fold, which corresponds to an estimated 33.8(49.6/25.1)-fold increase in harvest biomass, on average over two 18-month periods before and after November 2016 under different social conditions. In particular 121(278/74.9)-fold increase in profitability corresponding to an estimated 37.8(55.3/28.0)-fold increase in harvest biomass under high market accessibility, and a $55.0(126 / 34.0)$-fold increase in profitability corresponding to a $29.9(43.8 / 22.2)$-fold increase in harvest biomass under low market accessibility (see Methods). The on-site comparison at Mahadaga farm showed that synecoculture excelled in showing 258fold increase profitability in correspondence with an estimated 12.4-fold harvest biomass compared with the five other simultaneously tested alternative methods of sustainable farming.

A most dramatic change was the local reversal of the regime shift in the Mahadaga farm. From an analysis of satellite images taken before the experiment, the vegetation patches that surrounded Mahadaga farm corresponded to spotted vegetation patterns that strongly implied warning signals of imminent desertification $^{34}$. The subsequent intensive introduction of 150 edible plant species, including 40 staples, reestablished a lush ecosystem that maintained high productivity year-round that had positive regeneration effects on neighboring plots (Fig 2 (c1-c3)). 


\section{Climate resilience}

In all of the experiments conducted at the three sites, a significant positive correlation of plant species diversity with the fluctuation components of major meteorological parameters was observed, which could not be totally reduced to a correlation with the mean components (Fig 3 (b), Fig 4 (c), and Fig 5 (c) of the main text and Figs 2-4 of the Extended Data). Because of the non-linear relationships between the mean and standard deviation of meteorological parameters (bottom line of Figs 2-4 of the Extended Data), seasonality was weaker in the fluctuation than in the mean components, indicating that the observed biodiversity response may be an adaptive diversification of the species composition to climatic variability rather than seasonal patterns in community dynamics ${ }^{35}$. The observed positive correlation between the meteorological variance and plant species diversity in self-organized edible ecosystems implies the presence of evolutionary acquired biodiversity maintenance mechanisms, because increasing diversity to cope with environmental fluctuation generally contributes to sustain ecological community. We believe that it could constitute a fundamental mechanism to augment the climate resilience by mainstreaming biodiversity in food production ${ }^{36}$, which could provide an enhanced portfolio of agrobiodiversity beyond substitution and relocation of major $\mathrm{crops}^{37}$, and thereby enlarge the range of options to cope with the inevasible global biodiversity redistribution under climate change ${ }^{38}$ and keep the food systems within the planetary limits ${ }^{15,39}$.

\section{Discussion}

One of the greatest challenges in this study that seems contradictory to conventional monoculture methods is the stabilization of yield that relies on ecological niche formation. The rationale of synecoculture lies in productivity at the community level with a hyper-diverse portfolio of products and reduced input costs, which is compatible with the primary production of self-organized plant communities in natural environment $^{29}$. In Figure 5 of the Extended Data, although the fitted Pareto distributions for all experiments are situated in the parameter range where analytical mean converges to a finite value (i.e., $a>1$ ), a large deviation is inherent even at the annual scale (the 12-month gross profit ranged between 56 and $141 \%$ of the total average for the Mahadaga farm and was between 27 and 214\% of the total average for the Ise farm). Therefore, productivity in terms of arithmetic means is not a stable indicator for management. Still, the cumulative cost-benefit ratio converged to a higher level of performance compared with the conventional and other alternative methods (Figure 6 (a2) and (b2) of the Extended Data), which conforms to the theoretical prediction of power-law productivity and stability of harmonic means in our previous study $^{30}$. This is due to the positive correlation of productivity with introduced species diversity that develops over time, which is particularly enhanced in the ecological optimum production and performs increasingly better in marginal environments for both gains in gross profit and cost reductions (see total overyielding in Fig 1 of the main text and Figure 1 of Extended Data for the theoretical predictions, and Figure 6 (a1) and (b1) of the Extended Data for the measured data).

Not only the higher productivity of the Mahadaga farm, but also the ecological 
optimization with synecoculture could rebuild the power-law distribution of patch patterns and may help to prevent state shifts in the farm plots near the living area in a semi-arid environment ${ }^{34,40}$. The recovery and enhancement of diverse vegetation in farm plot represents a major shift from negative to positive externality on biodiversity in crop production ${ }^{14}$, which is also compatible with massive greening initiatives to reestablish a viable environment against desertification (e.g., ref. 41). It also sets a new baseline of increased crop diversity and yield against the declining trend in dryland $^{11}$, which can minimize land clearing and protect habitats of threatened large mammals especially in sub-Saharan Africa ${ }^{42}$, where animal-source foods are nutritionally valuable in food-deficient settings ${ }^{43}$. Given the importance of sustainability of smallhold farms and the positive social-ecological impacts that synecoculture could have, international initiatives in ECOWAS are being formed to better utilize the capacity of ecological optimum production, with a short-term goal to provide healthy and balanced diets to 3.5 million people impacted by COVID- $19^{44}$. Asia and sub-Saharan Africa will see the largest growth of agricultural emissions and will account for two-thirds of the increase in overall food demand by $2050^{45}$. In the face of climate change and current pandemics, food systems that support these regions and other nations harboring smallholders need to be scaled bottom up and should realize synergy between provisioning and regulating services (including pathogen suppression) that have been historically put in massive trade-off in agricultural land use ${ }^{1,3}$. In accordance with the biodiversity maintenance mechanisms that have been progressively revealed in the field of community ecology, our in-depth operational case studies imply that there exist fundamental principles that bring about such synergy through the leveraging of self-organized edible plant communities. It will lead to a novel typology for transformative change from resource- to management-intensive farming capable of creating essential biodiversity and ecosystem services in highly resilient form without resorting to fertilizers and agrochemicals. With appropriate development of supportive information technologies ${ }^{23,46}$ and sustainable distribution networks for various farm products ${ }^{47}$ and neglected and underutilized plant genetic resources ${ }^{48}$, ecological optimum production could be applicable to small-scale farms less than 5 ha that make up $94 \%$ of agricultural holdings ${ }^{49}$ and which combined with middle-scale farms less than 50 ha produce up to $77 \%$ of the major commodities and nutrients in the world ${ }^{50}$. Taken as a whole, the expansion and site-specific tailoring of human-augmented farming ecosystems has the potential to uplift the baseline of multiple ecosystem services globally and provide fundamental measures to cope with growing food demand and for proactive adaptation of various crop portfolio to climate change, which will introduce a human-driven form of resilience in biosphere integrity along with the expansion of essential human activities, by involving increasing population as a positive driver of biodiversity in Anthropocene ${ }^{14,29}$.

\section{Box 1. Integrated model of physiological and ecological optima (IMPEO) ${ }^{29}$.} The physiological optimum is the basis of monoculture optimization in agronomy, which is generally expressed as a unimodal distribution along the environmental gradient (Fig 1 (a)). In actual ecological situations, however, isolated growth is not fully attained and mixed communities are prevalent, which results in diverse shifting, 
division, and modification of the growth curve leading to the emergence of ecological niches (Fig 1 (b)). Random harvesting from various environments asymptotically converges the mean productivity to a normal distribution under the mean competition with other species, the plants can qualitatively be classified as those with central or marginal competence (orange and blue distributions, respectively, in Fig 1). Such differences generally produce competitive loss and symbiotic gain of productivity, and both contribute to the total overyielding in mixed communities (green distribution in Fig 1 (c)).

The contribution of symbiotic gain to the total overyielding in mixed polyculture could become increasingly significant as the mean environment shifts from a physiologically favorable condition (yellow background) to the marginal ranges (orange background), by creating new stretches of arable land in harsh conditions where little monoculture growth can be expected (red background).

See the Supplementary Information and Figure 1 of the Extended Data for the multi-dimensional version of IMPEO.

\section{Fig 1. Relationship between physiological and ecological optima and the total} effect of overyielding. (a) y-axis: examples of physiologically optimum isolated growth rate versus $\mathrm{x}$-axis: environmental parameters such as temperature, precipitation, sunlight, etc. (b) y-axis: primary productivity of various ecological niches in the same environment (x-axis) but mixed communities. (c) Top: random sampling from various niches in (a) (blue and orange dashed lines) and (b) (blue and orange solid lines) converges to normal distributions via the central limit theorem, their frequencies correspond to mean productivity measures such as harvest rate (yaxis) under averaged environmental conditions (x-axis). The overall productivity (green line) includes the productivities of plants of both growth-rate types.

(c) Bottom: Effects of symbiotic gain (blue line and arrows) and competitive loss (orange line and arrows) of plants with marginal and central competence, respectively, measured as the land equivalent ratio (LER) on the scale of $\mathrm{LER}^{\prime}:=\log (\log (\mathrm{LER})+$ 1). The main components of the total overyielding (green line) transit from centrally to marginally competent species as the environment shifts from the physiological optimum (yellow background) to marginal (orange background) and monoculture intolerant ranges (red background).

Fig 2. Synecoculture experimental plots. (a1-a4) Initial vegetation stages during the second year of crop species introduction from bare land in the temperate zone, in Oiso, Japan. After the construction of furrows in January, pictures show the transition of vegetation in (a1) early February, (a2) early May, (a3) late August, and (a4) late October. (b1) Pilot farm production experiment in the temperate zone, in Ise, Japan. Typical mixed polyculture state that augments diversity and productivity of vegetables in November is shown, with (b2) an example of the products packed in a delivery box. (c1-c5) Reversal of the regime shift in the semi-arid tropics, in Mahadaga, Burkina Faso. (c1) The control plot with no intervention remained bare for three years, while (c2) the introduction of 150 edible species established vigorous ecosystems including (c3) a strategic combination of crops with high density and vertical diversity. Partial regeneration of grass is observed in the background of ( $\mathrm{c} 1)$, which appears to be a positive effect from the neighboring synecoculture field (c2-c3). (c4) Little organic 
matter is visible in the image of the topsoil of the control plot, which is in contrast to (c5) showing the elaborated porous structure in the synecoculture plot.

\section{Fig 3. Spatial distribution and positive correlation with environmental variances} in the initial stage of ecologically optimum crop growth in the temperate zone. The initial-stage experiment in Oiso, Japan (Fig 2 (a1-a4)) shows that (a) the estimated inverse cumulative distribution of the number of different plant species versus the percentage of the surface they occupy is closer to a power-law distribution that reflects symbiotic interactions $\lambda=0$ than to an exponential distribution that merely reflects competition for resources $\lambda=1$. (b) There exist positive correlations between the mean number of observed species and the variance of meteorological parameters over the 30 days preceding the daily plot observation. There is no observable correlation with the means of the meteorological parameters. Mean plant species diversity versus mean and variance of three meteorological parameters are plotted with circles following the color gradient depicting the date. Black solid line: linear regression with less than 5\% significance; dashed line: linear regression with $95 \%$ confidence; dotted line: linear regression with prediction intervals.

Fig 4. Productivity of synecoculture experiment in the temperate zone. The fouryear production experiment in Ise, Japan shows (a) a power-law distribution of product sales with ( $b$ in the orange rectangle) asynchronous harvests of 78 kinds of crop. The $\mathrm{x}$-axis of (a) represents sales of each product in synecoculture on 1,000 sq.m (regularized productivity is daily and species-wise productivity in terms of Japanese yen (JPY) multiplied by the number of harvest events per year for synecoculture or yearly reported profit for conventional methods), both with an offset of total costs in order to compare the yearly mean profits (vertical solid lines) and costs (vertical dashed lines) summed as positive and negative values, respectively (see Methods). The dotted lines on the y-axis represent the estimated probability distributions for each production category based on the data shown as the rug plots along the x-axis. In (b) left, the 78 academic names of total synecoculture products are shown as a list with a color gradient, and the associated numbers define the value of the y-axis in (b) right, in which the sales for each product according to date on the x-axis is represented as the diameter of the circle with the same color gradient as the list.

The correlational analysis in (c) shows significant positive correlations between the number of produce types from synecoculture and meteorological variances for each 30-day interval. There was no significant correlation with the mean of the meteorological parameters.

Harvested crop diversity versus mean or variance of three meteorological parameters is plotted as circles following the color gradient of the date. Black solid line: linear regression with less than 5\% significance; dashed line: linear regression with $95 \%$ confidence; dotted line: linear regression with prediction intervals.

Fig 5. Productivity of synecoculture experiment in the tropical semi-arid zone. The three-year production experiment in Mahadaga, Burkina Faso shows a power-law distribution of product sales with (b in the red rectangle) asynchronous harvests of 37 kinds of crop. The x-axis of (a) represents sales of each product for synecoculture and for five alternative farming methods that were simultaneously tested on 500 sq.m (regularized productivity is daily and species-wise productivity in terms of West 
African CFA franc (XOF) multiplied by the number of harvest events per year for synecoculture and five alternative farming methods or yearly reported profit for the conventional methods), both with an offset of total costs in order to compare the yearly mean profits (vertical solid lines) and costs (vertical dashed lines) summed as positive and negative values, respectively (see Methods). The dotted lines represent the estimated probability distributions for each production category on the y-axis based on the data shown by the rug plots along the x-axis. The total productivity of synecoculture (red line and distribution) is shown on a monthly aggregated scale (orange distribution) and in the two periods before (cyan line and distribution) and after (magenta line and distribution) November 2016, which was the turning point of market accessibility (see Methods). In (b) left, the 37 academic names of total synecoculture products are shown as a list with a color gradient, and the associated numbers define the value of the $y$-axis in (b) right, in which the sales of each product according to date on the $\mathrm{x}$-axis is represented as the diameter of the circle with the same color gradient as the list.

The correlational analysis in (c) shows significant positive correlations between the number of produce types from synecoculture and meteorological variances for each 14-day interval. There are also significant negative correlations with the means of the meteorological parameters. Harvested crop diversity versus mean or variance of three meteorological parameters is plotted as circles following the color gradient of the year's date. Black solid line: linear regression with less than 5\% significance; dashed line: linear regression with $95 \%$ confidence; dotted line: linear regression with prediction intervals.

\section{Acknowledgments}

This study was funded by Sony CSL. The field experiment in Oiso, Japan was supported by Kiyomi Kondo-Nishikata. The synecoculture production experiment in Ise, Japan was conducted by Sakura Shizenjyuku, Inc. under the direction of Takashi Otsuka, and in Mahadaga, Burkina Faso by Agence de Formation et d'Ingénierie du Développement Rural Autogéré (AFIDRA) and Centre Africain de Recherche et de Formation en Synécoculture (CARFS) under the direction of André Tindano. Hidemori Yazaki, Kousaku Ohta, Tatsuya Kawaoka, Kazuhiro Takimoto, and Shuntaro Aotake contributed as research assistants at Sony CSL. Extended Data Figure 1 was drawn by courtesy of Kei Fukuda.

\section{References $\mathbf{- 5 0}$}

1. Barnosky, A. D. et al. Approaching a state shift in Earth's biosphere. Nature 486, 52-58 (2012).

2. Ripple, W. J. et al. World Scientists' Warning to Humanity: A Second Notice. BioScience 67, 1026-1028 (2017).

3. Díaz, S. et al. Pervasive human-driven decline of life on Earth points to the need for transformative change. Science 366, eaax3100 (2019).

4. Intergovernmental Science-Policy Platform on Biodiversity and Ecosystem Services (IPBES). Global assessment report on biodiversity and ecosystem services of the Intergovernmental Science-Policy Platform on Biodiversity and Ecosystem Services. IPBES secretariat, Bonn, Germany (2019). 
5. McDowell, N. G. et al. Pervasive shifts in forest dynamics in a changing world. Science 368, eaaz9463 (2020).

6. Ceballos, G., Ehrlich, P. R. \& Raven, P. H. Vertebrates on the brink as indicators of biological annihilation and the sixth mass extinction. Proc. Natl. Acad. Sci. USA 117, 13596-13602 (2020).

7. Sánchez-Bayo, F. \& Wyckhuys, K. A. G. Worldwide decline of the entomofauna: A review of its drivers. Biol. Conserv. 232, 8-27 (2019).

8. Diaz, R. J. \& Rosenberg R. Spreading dead zones and consequences for marine ecosystems. Science 321, 926-929 (2008).

9. Smith, P. et al. in Climate Change 2014: Mitigation of Climate Change. Contribution of Working Group III to the Fifth Assessment Report of the Intergovernmental Panel on Climate Change (eds Edenhofer, O. et al.) 2014: Agriculture, Forestry and Other Land Use (AFOLU). (Cambridge University Press, 2014).

10. Steffen, W. et al. Planetary boundaries: Guiding human development on a changing planet. Science 347, 1259855 (2015).

11. The Intergovernmental Panel on Climate Change (IPCC). Global Warming of $1.5^{\circ}$ Global Warming of $1.5^{\circ}$ C.An IPCC Special Report on the impacts of global warming of $1.5^{\circ} \mathrm{C}$ above pre-industrial levels and related global greenhouse gas emission pathways, in the context of strengthening the global response to the threat of climate change, sustainable development, and efforts to eradicate poverty. Masson-Delmotte, V. et al. (eds.) (2018).

12. Convention on Biological Diversity (CBD). Key messages from the workshop on "biodiversity and climate change: integrated science for coherent policy". https://www.cbd.int/doc/c/c429/2df7/dc8cc589bbf1f5b58f8a1d63/cop-14inf-22- en.pdf (2018). See also IPBES Pandemics Report: https://ipbes.net/pandemics (2020)

13. Costanza, R. et al. Twenty years of ecosystem services: How far have we come and how far do we still need to go? Ecosyst. Serv. 28, 1-16 (2017).

14. Funabashi, M. Human augmentation of ecosystems: objectives for food production and science by 2045. NPJ Sci. Food 2018, 2: 16 (2018).

15. Erb, K. -H. et al. Exploring the biophysical option space for feeding the world without deforestation. Nat. Commun. 7, 11382 (2016).

16. Bastin, J. -F. et al. The global tree restoration potential. Science 365, 76-79 (2019).

17. Sattari, S. Z., Bouwman, A. F., Rodríguez, R. M., Beusen, A. H. W. \& van Ittersum, M. K. Negative global phosphorus budgets challenge sustainable intensification of grasslands. Nat. Commun. 7, 10696 (2016).

18. Machmuller, M. B. et al. Emerging land use practices rapidly increase soil organic matter. Nat. Commun. 6, 6995 (2015).

19. Veldman, J. W. et al. Comment on "The global tree restoration potential". Science 366, eaay7976 (2019).

20. Lesiv, M. et al. Estimating the global distribution of field size using crowdsourcing. Glob. Chang. Biol. 25, 174-186 (2019).

21. Altieri, M. A. Agroecology: the science of natural resource management for poor farmers in marginal environments. Agr. Ecosyst. Environ. 93, 1-24 (2002).

22. Tokoro, M. Open Systems Science: A Challenge to Open Systems Problems. 

(Bourgine, P., Collet, P. \& Parrend, P. eds.) pp. 213-221 (Springer International Publishing, Switzerland, 2017).

23. Funabashi, M. et al. Foundation of CS-DC e-laboratory: Open Systems Exploration for Ecosystems Leveraging. in First Complex Systems Digital Campus World E-Conference 2015 (Bourgine, P., Collet, P. \& Parrend, P. eds.) pp. 351-374 (Springer International Publishing, Switzerland, 2017).

24. Schork, N. J. Personalized medicine: Time for one-person trials. Nature 520, 609-611 (2015).

25. Rose, S. M. S. -F. et al. A longitudinal big data approach for precision health. Nat. Med. 25, 792-804 (2019).

26. Tilman, D. Diversity and productivity in a long-term grassland experiment. Science 294, 843-845 (2001).

27. Scanlon, T. M., Caylor, K. K., Levin, S. A. \& Rodriguez-Iturbe, I. Positive feedbacks promote power-law clustering of Kalahari vegetation. Nature 449, 209-212 (2007).

28. Kéfi, S. et al. Spatial vegetation patterns and imminent desertification in Mediterranean arid ecosystems. Nature 449, 213-217 (2007).

29. Funabashi, M. Synecological farming: Theoretical foundation on biodiversity responses of plant communities. Plant Biotechnol. 32, 1-22 (2016).

30. Funabashi, M. Augmentation of plant genetic diversity in Synecoculture: theory and practice in temperate and tropical zones. in Genetic Diversity in Horticultural Plants (Nandwani, D. eds.) pp.3-46 (Springer International Publishing, Switzerland, 2019).

31. Smith, J., Yeluripati, J., Smith, P. \& Nayak, D. R. Potential yield challenges to scale-up of zero budget natural farming. Nat. Sustain. 3, 247-252 (2020).

32. Lange, M. et al. Plant diversity increases soil microbial activity and soil carbon storage. Nat. Commun. 6, 6707 (2015).

33. Funabashi, M. Synecological farming for mainstreaming biodiversity in smallholding farms and foods: implication for agriculture in India. Indian J. Plant Genet. Resour. 30, 99-114 (2017).

34. Kéfi, S. et al. Early Warning Signals of Ecological Transitions: Methods for Spatial Patterns. PLoS One 9, e92097 (2014).

35. Funabashi, M. The 10,000th year version of agriculture. in Science of genes, diversity, and circulation Toward the fusion of ecology domains (in Japanese) (Kadowaki, K. \& Tachiki, Y. eds.) (Kyoto University Press, Japan, 2019).

36. IIED \& UNEP-WCMC. Mainstreaming biodiversity and development: guidance from African experience 2012-17. IIED, London. (2017).

37. Rippke, U. et al. Timescales of transformational climate change adaptation in sub- Saharan African agriculture. Nat. Clim. Chang. 6, 605-609 (2016).

38. Pecl, G. T. et al. Biodiversity redistribution under climate change: Impacts on ecosystems and human well-being. Science 355, eaai9214 (2017).

39. Springmann, M. et al. Options for keeping the food system within environmental limits. Nature 562, 519-525 (2018).

40. Berdugo, M., Kéfi, S., Soliveres, S. \& Maestre, F. T. Plant spatial patterns 
identify alternative ecosystem multifunctionality states in global drylands.

Nat. Ecol. Evol. 1,0003 (2017).

41. The Great Green Wall https://www.greatgreenwall.org/

42. Tilman, D. et al. Future threats to biodiversity and pathways to their prevention. Nature

546, 73-81 (2017).

43. de Bruyn, J. et al. Food composition tables in resource-poor settings: exploring current limitations and opportunities, with a focus on animal-source foods in subSaharan Africa. Br. J. Nutr. 116, 1709-1719 (2016).

44. ECOWAS Commission Regional Agency for Agriculture and Food "Appui à la Transition Agro-écologique au Mali par la Synécoculture (ATAMS)" in the Results of the selecting projects of the sixth call for proposals of the Regional Agency for Agriculture and Food on the "Project of support of agroecological transition in West Africa" $\underline{\mathrm{h}}$ $\underline{\mathrm{ttp}}$ ://araa.org/sites/default/files/attachments/Resullts $\% 20$ of $\% 20$ the $\% 20$ selecting $\%$ $\underline{20 p}$ rojects.pdf; and the Togolese Republic COVID-19 relief project "Potager Solidaire" https://synecoculture.sonycsl.co.jp/public/20200917\%20Fiche $\% 20 \mathrm{de} \% 20$ Projet $\%$ 20POTAGER\%20SOLIDAIRE.pdf

45. Alexandratos, N. \& Bruinsma, J. World agriculture towards 2030/2050: the 2012 revision. ESA Working paper No. 12-03. Rome, FAO. (2012).

46. Stephenson, P. J. et al. Unblocking the flow of biodiversity data for decisionmaking in Africa. Biol. Conserv. 213, 335-340 (2017).

47. Frelat, R. et al. Drivers of household food availability in sub-Saharan Africa based on big data from small farms. Proc. Natl. Acad. Sci. USA 113, 458-463 (2015).

48. Jaenicke, H., Ganry, J., Hoeschle-Zeledon, I. \& Kahane, R. (eds.) International symposium on underutilized plants for food security, nutrition, income and sustainable development. Arusha, Tanzania. ISBN 978-90-66057-01-2 (2009)

49. Lowder, S. K., Skoet, J. \& Raney, T. The number, size, and distribution of farms, smallholder farms, and family farms worldwide. World Dev. 87, 16-29 (2016).

50. Herrero, M. et al. Farming and the geography of nutrient production for human use: a transdisciplinary analysis. Lancet Planet. Health 1, e33-e42 (2017). 


\section{Methods Summary}

553 We developed a theory that connects the differing definitions of productivity of monoculture-based optimization in agronomy and mixed community-based growth in ecology, which defines the protocol of synecological farming (synecoculture) as an extreme typology of plant food production based on self-organized ecological niches of a highly diverse community of crops and other spontaneous vegetation.

558 Three small-scale plots representative of the basic smallest surface for smallholders

559 were prepared in Japan and Burkina Faso following the protocol of synecoculture, 560 and maintained without the use of tillage, fertilizers, or agrochemicals.

561 We measured the species-wise surface in a small harvest-free surface in Japan and 562 analyzed whether the vegetation patch pattern followed a power law that reflects 563 symbiotic interaction between plants or an exponential distribution based merely on 564 the competition of resources.

565 Two production experiments in Japan and Burkina Faso were performed in 566 collaboration with commercial farms with market access. A wide variety of species567 wise product sales was recorded and the statistical properties of the time series were 568 analyzed in comparison with official statistics on productivity and the cost of 569 conventional market gardening and other parallelly tested farming methods.

570 In all experiments, we compared the mean and variance parameters of 571 meteorological records of the finest satellite open data with the observed plant 572 diversity and analyzed statistical correlation that represents the biodiversity response 573 to a changing environment during the growth period. 


\section{Simulation of the integrated model of physiological and ecological optima (IMPEO): Box 1 and Fig 1.}

Based on ref. 29, we simulated a typical scenario of overyielding with a mixed polyculture of two plant species. First, let us describe the unimodal distribution of physiological growth of two species with the same physiological optimum range (Fig 1 (a)). We define this distribution as $U\left(E n v ; v_{p}\right)$ with an environmental parameter Env and its physiologically optimum value $v_{p}$ giving the maximum growth rate. The emerging ecological niches through interactions between the two species and the environment have several typologies, such as shifting and division, and other modifications of the growth curve, which are impossible to simulate precisely (Fig 1 (b)). Nevertheless, we will assume that there are qualitatively two different types of niche differentiation dynamics: 1) One plant type shows the superiority in growth of the physiological optimum to the other species (i.e., central competence expressed as the orange distributions in Fig 1 (b));2) The other plant type shows superiority in regard to growth in the marginal condition relative to the physiologically favorable range (i.e., marginal competence expressed as the blue distributions in Fig 1 (b)).

Let us describe the diverse ecological niches as $G R_{c}=E N_{c}\left(E n v ; v_{c}, \sigma_{c}\right)$ for centrally competent species and $G R_{m}=E N_{m}\left(E n v ; v_{m}, \sigma_{m}\right)$ for marginally competent species under the following assumptions, $v_{c}=v_{m}=v_{p}$ and $\sigma_{c}<\sigma_{m}$, where $G R_{c}$ and $G R_{m}$ stand for the growth rates, Env is an environmental parameter, and $v_{c}, v_{m}$ and $\sigma_{c}, \sigma_{m}$ are the means and standard deviations of Env for centrally and marginally competent species, respectively. For simplicity, we set the same surface ratio between centrally and marginally competent species, but the model is valid for any arbitrary ratio of mixed polyculture.

Random harvesting from all environments in those niches (i.e., random sampling from the growth rate distributions $G R_{c}$ and $G R_{m}$ ) results in a normal distribution of mean productivity through the central limit theorem, such that $H R_{c} \sim N\left(E[E n v] ; v_{c}, \sigma_{c}\right)$ and $H R_{m} \sim N\left(E[E n v] ; v_{m}, \sigma_{m}\right)$, where $N(\cdot ; v, \sigma)$ is a normal distribution with mean $v$ and standard deviation $\sigma, H R_{c}$ and $H R_{m}$ respectively represent the harvest rate of centrally and marginally competent species of the mean environmental parameter $E[E n v]$ over the sampling. We can also obtain the mean monoculture productivity $U^{\prime} \sim N\left(E[E n v] ; v_{p}, \sigma_{p}\right)$ by using the same sampling method, which results in $\sigma_{c}<\sigma_{p}<\sigma_{m}$. In Fig 1 (c) top, $H R_{c}$ is depicted as an orange line, $H R_{m}$ as a blue line, and $H R_{c}+H R_{m}$ as a green line. The parameters $\sigma_{p}=20, \sigma_{c}=19.7$, and $\sigma_{m}=40$ were typical values chosen to illustrate the effects of competitive loss (orange arrows) and symbiotic gain (blue arrows). In Fig 1 (c) bottom, the land equivalent ratio (LER) ${ }^{51}$ is the value calculated between the mean monoculture productivity $U^{\prime}$ and its polyculture counterparts $H R_{c}$ and $H R_{m}$, as $L E R=\frac{H R_{c}+H R_{m}}{U^{\prime}}$ (green line), and its species-wise components $\frac{H R_{c}}{U^{\prime}}$ (orange line) and $\frac{H R_{m}}{U^{\prime}}$ (blue line). These LER components are depicted on a scale of $\mathrm{LER}^{\prime}:=\log (\log (\mathrm{LER})+1)$, where the straight dotted black line is the separatrix $\mathrm{LER}^{\prime}=0$ between symbiotic gain (upper part, LER $>0$ ) and competitive loss (lower part, LER' $<0$ ). 


\section{Implementation of synecological farming (synecoculture) in Oiso and Ise, Japan and Mahadaga, Burkina Faso (Fig 2).}

Following the protocol of synecoculture farming method, the following three ecosystems were started from bare ground ${ }^{23,52,53}$ :

- Field A: From January 2010 to December 2011, randomly mixed communities of 52 edible plant species and other naturally occurring species on 420 sq.m without harvesting or watering and little weed maintenance in Oiso, Japan (GPS coordinates in decimal degrees: $35.31675,139.32515$ ).

- Field B: From April 2008, a preliminary observation of ecological niches of various plant species; from June 2010 to May 2014, a strategically mixed association of 133 edible plant species and other naturally occurring species on a commercial farm of 1,000 sq.m with harvesting and occasional watering and weed maintenance in Ise, Japan (GPS coordinates in decimal degrees: 34.53022, 136.6873).

- Field C: After the introduction of seeds and seedlings on March 2015, from June 2015 to May 2018, a strategically mixed association of 150 edible plant species on a commercial farm of 500 sq.m with harvesting, watering, and a small amount of weed maintenance in Mahadaga, Tapoa province, Burkina Faso (GPS coordinates in decimal degrees: 11.72328, 1.76136).

For all implementations, only seeds and seedlings and necessary water as specified were introduced in the fields. No synthetic and organic fertilizers, no agrochemicals or other phytosanitary products, no ground cover materials, and no other amendments were used. No agricultural machinery was used, except for a small handy mower in the field B. No external financial support was given to the commercial synecoculture farms (field B and C).

\section{Surface distribution analysis and correlation analysis between species diversity} and meteorological parameters at the synecoculture field in Oiso, Japan (Fig 3). The covering surface of each plant species at low ground level in field A was measured with the 2 -step visual analog scale method ${ }^{33}$ on 80 sections measuring 2 sq.m each, 22 times at an interval of 1 week to 1.5 months (about once every 2.3 weeks on average) at a frequency depending on the degree of growth during January - December 2011 [Supplementary Data 1]. The observed plant species were categorized into 1) introduced crop species and 2) naturally occurring spontaneous species, which were also parallelly labeled as 3) edible species that were utilized and 4) non-edible species that were not yet utilized as synecoculture products.

In Fig 3 (a), the inverse cumulative distribution of the number of different species is plotted with respect to the minimum threshold of yearly averaged covering surface ratio. Theoretical models show that the size distribution of self-organized vegetation surface tends to an exponential distribution that reflects competition between plants for resources, but that it tends to a power-law distribution when there is locally symbiotic relationship ${ }^{27,28}$. This assumption applies to the analysis of both the inverse-cumulative and non-cumulative distributions, since power-law and exponential functions are conserved under the transformation from a probability density to its cumulative distribution. The experiment in Oiso focused on measuring 
the relative degree of contribution between local symbiotic interactions and resource competition at the inter-species level (i.e., symbiotic gain and competitive loss in IMPEO) through an analysis of the species-wise averaged surface distribution. We devised an integrative model to evaluate the goodness of fit between the power-law and exponential distributions:

$$
\log Y=A \cdot \operatorname{Box} \operatorname{Cox}(X, \lambda)+B
$$

where $\operatorname{Box} \operatorname{Cox}(X, \lambda)=\left\{\begin{array}{l}\frac{X^{\lambda}-1}{\lambda}(1 \geq \lambda>0) \\ \log X(\lambda=0)\end{array}\right.$ is the Box-Cox transformation with a continuous parameter $1 \geq \lambda \geq 0$, which converges to an exponential distribution $\log Y=A \cdot X-A+B$ in the $\lambda=1$ case and a power-law distribution $\log Y=A$. $\log X+B$ in the $\lambda=0$ case. The fitting was performed using the bcPower() and nls() functions in $\mathrm{R}^{54}$.

In Fig 3 (b), mean species diversity in daily observed sections versus the mean and standard deviation of major meteorological parameters during the past 30 days from the observation (substantial growth period of the crops in the field) are plotted. Complete plots are shown in Figure 2 of the Extended Data. Eight parameters representing major environmental factors for plant growth (temperature, humidity, and sunlight) in an area measured at a daily $1-\mathrm{km}$ grid resolution from December 2010 to December 2011 were obtained from the Agro-Meteorological Grid Square Data System, NARO (https://amu.rd.naro.go.jp//) ${ }^{55}$ : daily mean air temperature, daily maximum air temperature, daily minimum air temperature, daily precipitation (reanalysis), mean relative humidity, global solar radiation, downward long-wave radiation, and sunshine duration. The correlation analysis was performed using the $\operatorname{lm}()$ function in $\mathrm{R}^{54}$.

\section{Productivity analysis and correlation analysis of species diversity and meteorological parameters of synecoculture field in Ise, Japan (Fig 4).} 78 kinds of vegetable and fruit products were harvested from field $\mathrm{B}$ and sold as delivery boxes from January 2011 to February 2014 at a price rate of 315 JPY per 100 $\mathrm{g}$, which is approximately equivalent to the rate for certified organic products (about 1.5 times higher than the price of conventional farm products) in the same region [Supplementary Data 2]. From June 2010 to May 2014, other edible plant products, seeds and seedlings were also occasionally harvested and sold on-site, including as ingredients for a local restaurant; the data are summarized for each month [Supplementary Data 3]. The principal cost was comparable to that of the conventional methods and comprised the cost of seeds and seedlings [Supplementary Data 4].

Yearly average data of productivity (gross profit in JPY) and material costs (seeds and seedlings, fertilizers and other amendments, materials such as plastic mulch, and machinery such as a tractor) of open-field conventional market gardening during 2010-2014 were obtained from the online database provided by the Ministry of Agriculture, Forestry and Fisheries in Japan ${ }^{56}$. These datasets were converted into amounts per 1,000 sq.m. The probability density functions shown in Fig 4 (a) were numerically estimated using the density() function in $\mathrm{R}^{54}$.

To compare the yearly summed productivity of the conventional methods and with the daily recorded productivity of synecoculture, the scale of the x-axis of Fig 4 (a) is each unit sale multiplied by the number of harvest events per year. The 
conventional data consists of the yearly mean gross profit $X_{c}=\sum_{i=1}^{n} c_{i}$ that comprise those of $n$ harvest events $\left\{c_{i}\right\}$, which are not explicitly shown in the dataset. $n$ is usually small (a few times per year for each crop), and $\left\{c_{i}\right\}$ follows a normal distribution because it is based on a large sum of simultaneous harvests of monoculture crops; therefore, $X_{c}$ is a good representative value of $\left\{c_{i}\right\}$. One can compare $X_{c}$ with the yearly summed gross profit of synecoculture $X_{s}=\sum_{i=1}^{m} s_{i}$ based on the record of $m$ harvest events $\left\{s_{i}\right\}$ in daily and species-wise resolution, which is shown as vertical solid lines and rug plots in Fig 4 (a). In synecoculture, $m$ is large (yearly average, $m=285$ for the Ise farm and $m=3619$ for the Mahadaga farm), and $\left\{s_{i}\right\}$ follow a power-law distribution (also plotted in Figure 5 of the Extended Data). Therefore, $\left\{s_{i}\right\}$ contains a large deviation from $X_{s}$. In order to plot $\left\{s_{i}\right\}$ on a compatible scale with $X_{c}$ and $X_{s}$, we need to define the regularized productivity $r_{i}=$ $m \cdot s_{i}$ (daily and species-wise productivity $s_{i}$ multiplied by the number of harvest events $m$ on a yearly scale), because in that way the mean value of $\left\{r_{i}\right\}$ coincides with $X_{s}$, i.e., $X_{s}=\sum_{i=1}^{m} s_{i}=\sum_{i=1}^{m} m \cdot s_{i} / m=\frac{1}{m} \sum_{i=1}^{m} r_{i}$, regardless of the frequency of harvest events. The same scale applies to the yearly costs that are expressed as a negative offset to gross profit, which is depicted with the vertical dashed lines in Fig 4 (a).

The correlation between the number of produce types (product diversity measured by the number of different species) sold as delivery box and the mean and standard deviation of eight major meteorological parameters ${ }^{55}$ (same as in the Oiso experiment) for each 30-day interval was analyzed. Typical results are shown in Fig 4 (c); complete plots are shown in Figure 3 of the Extended Data.

\section{Productivity analysis and correlation analysis between species diversity and meteorological parameters of synecoculture field in Mahadaga, Burkina Faso} (Fig 5).

Products from 37 plant species in field $\mathrm{C}$ were harvested and sold at a local market from June 2015 to May $2018^{53,57,58}$. The price rate was set to those of organic products (about two times higher than conventional products) from June 2015 to May 2017, and to the prices of conventional products from June 2017 to May 2018, because of deterioration of local security situation and consequent loss of customers.

Five alternative methods that aim for sustainable farming were also tested alongside the synecoculture production during the same period, namely 1: a system of rice intensification and trees, 2 : conservation agriculture, 3: permaculture, 4: biointensive market gardening, and 5: traditional market gardening. We obtained the gross profit of synecoculture sales at a daily resolution [Supplementary Data 5] and those of the five alternative methods in terms of the monthly aggregated sum [Supplementary Data 6], together with the monthly installation, materials and working costs [Supplementary Data 7].

Conventional market gardening data based on the estimation of ten crops in Burkina Faso was obtained from a Food and Agriculture Organization of the United Nations (FAO) document ${ }^{59}$ on standards of gross profit and costs, which included only installation and water costs and excluded other operation costs such as seeds and seedlings, fertilizer and phytosanitary products, and materials and working costs.

Datasets of gross profit and costs of the five alternative and conventional 
methods were converted into amounts per 500 sq.m. The probability density functions in Fig 5 (a) were numerically estimated using the density() function in $\mathrm{R}^{54}$. The $\mathrm{x}$-axis in Fig 5 (a) conforms to that of Fig 4 (a).

In regard to Fig 5 (c), satellite meteorological data corresponding to the Mahadaga farm at a daily 19.2-km grid resolution was obtained from (http://climengine.appspot.com $/)^{60}$. From which, 19 major parameters related to plant growth were taken from the Climate Forecast System (CFS) Reanalysis dataset of the National Centers for Environmental Prediction (NCEP): maximum temperature, mean temperature, minimum temperature, potential evaporation, precipitation, specific humidity, maximum specific humidity, minimum specific humidity, 5 -cm soil moisture, $25-\mathrm{cm}$ soil moisture, $70-\mathrm{cm}$ soil moisture, $150-\mathrm{cm}$ soil moisture, net radiation, downward shortwave radiation, upward shortwave radiation, downward longwave radiation, upward longwave radiation, latent heat flux, and sensible heat flux.

The correlation between the number of produce types (product diversity measured by the number of different species) and the means and standard deviations of the meteorological parameters for each 14-day interval (a substantial period of growth of crops in the field) were analyzed. Typical results are illustrated in Fig 5 (c); the complete plots are shown in Figure 4 of the Extended Data.

\section{Estimation of harvest biomass from product sales}

Although the land equivalent ratio (LER) ${ }^{51}$ is used to evaluate polyculture productivity, it is not suitable for evaluating highly diverse mixed polycultures for two reasons:

1. For any probability distribution with the mean $v$ and standard deviation $\sigma$, the effect of fluctuations expressed as a ratio $\frac{v \pm \sigma}{v \pm \sigma}$ is not symmetric with respect to the standard ratio $\frac{v \pm 0}{v \pm 0}=1$, which results in the LER having a positive bias; e.g., $\left(\frac{v+\sigma}{v+\sigma}+\frac{v-\sigma}{v+\sigma}+\frac{v+\sigma}{v-\sigma}+\frac{v-\sigma}{v-\sigma}\right) / 4=v^{2} / v^{2}-\sigma^{2}>1$.

Therefore, even if the monoculture and polyculture productivities are equal, the effect of fluctuation in LER gives a positive bias to polyculture.

2. Actual monoculture productivity data is a weighted sum of many monoculture $\operatorname{crops}^{56,59}$, which is equivalent to a polyculture based on a mosaic of different monoculture surfaces. Therefore, the proportion of each crop surface within a given social-ecological context affects the overall productivity, which is not considered to be a realistic constraint in LER.

To overcome this pitfall, we defined the relative biomass ratio (BR) that represents the community-based land equivalent ratio as follows:

$$
B R:=\frac{\sum_{i=1}^{k} X_{i}}{\sum_{j=1}^{l} Y_{j}}
$$

Where $X_{i}$ is the mixed polyculture yield $(k>1$ crops are mixed together on the same surface) of the $i$ th crop, and $Y_{j}$ is the mosaic polyculture yield (a combination of separate monocultures with $l>1$ different crops on the same surface area) of the $j$ th crop. Note that BR coincides with $L E R:=\sum_{i=1}^{k} \frac{X_{i}}{U^{\prime}}$ in the IMPEO of one or more crops with the same physiological growth curve $U^{\prime}$. 
In the case that $k$ crops for $P_{i}$ are included in the $l$ crops of $Q_{j}$, which is the case for field $\mathrm{B}$, it is possible to calculate the BR of the mixed polyculture products using the sales data weighted with the per-price weight of each crop:

$$
B R:=\frac{\sum_{i=1}^{k} P_{i} \cdot V_{i}}{\sum_{j=1}^{l} Q_{j} \cdot W_{j}}
$$

Where $P_{i}$ and $Q_{j}$ are the productivity measured by the sale price, $V_{i}$ and $W_{j}$ are product biomass per unit price for each $\operatorname{crop}\left(X_{i}=P_{i} \cdot V_{i}\right.$ and $\left.Y_{j}=Q_{j} \cdot W_{j}\right)$. In this study, the price rate $R$ of Synecoculture products are set as $R:=\frac{W_{i}}{V_{i}} \fallingdotseq 1.5$ in field $\mathrm{B}$. For field $\mathrm{C}, R \fallingdotseq 2.0$ and $R \fallingdotseq 1.0$ for the first two years and the third year, respectively.

In sufficiently diverse sets of crops, the average product biomass per price defined as $V:=\frac{\sum_{i=1}^{k} P_{i} \cdot V_{i}}{\sum_{i=1}^{k} P_{i}}$ and $W:=\frac{\sum_{j=1}^{l} Q_{j} \cdot W_{j}}{\sum_{j=1}^{l} Q_{j}}$ converge to finite values, and their ratio converges to $R$, such that $\frac{W}{V} \approx R$. Using these relationships, the estimation of $\mathrm{BR}$ is obtained as follows:

$$
B R \approx \frac{V \cdot \sum_{i=1}^{k} P_{i}}{W \cdot \sum_{j=1}^{l} Q_{j}}=\frac{\sum_{i=1}^{k} P_{i} / R}{\sum_{j=1}^{l} Q_{j}}
$$

If $k$ crops for $P_{i}$ are not totally included in the $l$ crops of $Q_{j}$, which is the case of field $\mathrm{C}$, we considered the possible variable range of conventional productivity based on the median and $25^{\text {th }}$ and $75^{\text {th }}$ percentiles of productivity in $l$ crops (see also Figure 6 (b2) of the Extended Data).

This estimated biomass does not include the biomass of the established ecosystem permanently present in the synecoculture field, such as trees and seedlings, naturally occurring non-edible plants, fallen leaves, stems after harvest, and highly developed root systems that are sources of soil organic matter.

\section{Power-law fitting of surface distribution and harvest sales in Figure 5 of the Extended Data.}

The probability density (y-axis) of the following variables (x-axis) was estimated using the density() function in $\mathrm{R}$ and linearly fitted with a Pareto distribution $Y=$ $\frac{a b^{a}}{X^{a+1}}$ on a double-logarithmic scale by using the $\operatorname{lm}()$ function in $\mathrm{R}^{54}$.

Field A: Species-wise surface percentage data for 80 2-sq.m sections in Oiso [Supplementary Data 1]. Surface data above 5\% and the estimated probability density were used for the fitting.

Field B: Crop-wise daily sales data of the delivery box from the Ise farm [Supplementary Data 2]. Sales data above 1,000 JPY and the estimated probability density above $1.0 \mathrm{e}-7$ were used for the fitting. Field C: Crop-wise daily sales data of the Mahadaga farm [Supplementary Data 5]. Sales data above 1,000 XOF and the estimated probability density above 1.0e-7 were used for the fitting. 


\section{References}

51. Mead, R. \& Willey, R. W. The concept of a 'land equivalent ratio' and advantages in yields from intercropping. Exp. Agric. 16, 217-228 (1980).

52. Funabashi, M. (editor) Synecoculture Manual 2016 Version (English Version) Research and Education material of UniTwin UNESCO Complex Systems Digital Campus, e- laboratory: Open Systems Exploration for Ecosystems Leveraging, No.2. (2016).

53. Tindano, A. \& Funabashi, M. (eds) Proceedings of the 1st African Forum on Synecoculture (English Version). Research and Education material of UniTwin UNESCO Complex Systems Digital Campus, e-laboratory: Open Systems Exploration for Ecosystems Leveraging, No.5. (2017).

54. R version 3.6.0 https://www.r-project.org/

55. Ohno, H., Sasaki, K., Ohara, G. \& Nakazono, K. Development of grid square air temperature and precipitation data compiled from observed, forecasted, and climatic normal data. Climate in Biosphere, 16, $71-79$ (in Japanese with English title) (2016).

56. MAFF e-stat http://www.e-stat.go.jp/SG1/estat/List.do?lid=000001089733 Ministry of Agriculture, Forestry and Fisheries of Japan

57. Tindano, A. \& Funabashi, M. (eds) Proceedings of the 2nd African Forum on Synecoculture (English Version). Research and Education material of UniTwin UNESCO Complex Systems Digital Campus, e-laboratory: Open Systems Exploration for Ecosystems Leveraging, No.7. (2018).

58. Tindano, A. \& Funabashi, M. (eds) Proceedings of the 3rd African Forum on Synecoculture (English Version). Research and Education material of UniTwin UNESCO Complex Systems Digital Campus, e-laboratory: Open Systems Exploration for Ecosystems Leveraging, No. 10. (2018).

59. FAO EASYPol. Analyse de la filière maraichage au Burkina Faso. Ressources complémentaires, Module EASYPol 107 http://www.fao.org/docs/up/easypol/887/analyse-filiere-maraichage_107fr.pdf (2017)

60. Huntington, J. L. et al. Climate Engine: cloud computing and visualization of climate and remote sensing data for advanced natural resource monitoring and process understanding. Bull. Amer. Meteor. Soc. 98, 2397-2410 (2017).

[Supplementary Data 1] Supplementary Data 1: Surface data of Oiso experiment. Will obtain doi after review

[Supplementary Data 2] Supplementary Data 2: Daily sales data of delivery box of Ise farm.

Will obtain doi after review

[Supplementary Data 3] Supplementary Data 3: Monthly on-farm sales data of Ise farm. Will obtain doi after review

[Supplementary Data 4] Supplementary Data 4: Monthly cost data of Ise farm. Will obtain doi after review

[Supplementary Data 5] Supplementary Data 5: Daily sales data of Synecoculture in Mahadaga farm. Will obtain doi after review [Supplementary Data 6] Supplementary Data 6: Monthly sales data of five alternative methods in Mahadaga farm. Will obtain doi after review 
890 [Supplementary Data 7] Supplementary Data 7: Monthly cost data of Mahadaga

891 farm. Will obtain doi after review

892

893 


\section{Supplementary Information \& Figures and Tables of the Extended Data $(<10$ figures and tables)}

\section{Multi-dimensional IMPEO}

The environmental parameter in Fig. 1 is generally multi-dimensional. In such cases, the IMPEO is expressed with multi-dimensional normal distributions. Figure 1 of the Extended Data shows a typical representation of IMPEO with two-dimensional environmental parameters. Mean environmental parameters Env1 and Env2 that define the physiological optimum generally represent macroscopic culture conditions such as air temperature, precipitation, and solar radiation, but they can also be influenced by ecosystem dynamics and produce a variety of changes in microclimate such as soil temperature augmented by microbiological activities, soil moisture that depends on soil porosity, and actual luminosity on the leaf surface shaded by other plants.

The optimum production range in conventional monoculture systems often ignores an important part of these parameters that may show the superiority of ecological optimum growth with mixed polyculture. For example, physiological optimization of the parameter Env1 does not necessarily guarantee the superiority of monoculture production if another important parameter Env2 remains marginal; in such case, the physiological optimum for Env1 remains lower than the ecological optimum (e.g., monoculture millet production with and without association of other shrubs ${ }^{61}$ ). The results of the experiment in Burkina Faso imply that the conventional monoculture method was not totally optimized, and the changes in microclimate and soil environment affected by community dynamics dramatically improved the polyculture productivity in synecoculture.

\section{Extended Data Figure 1.}

Left: Two-dimensional IMPEO. For simplicity, the case of a single crop without correlation between the mean environmental parameters is depicted.

\section{Right: Two sections with fixed Env2.}

(a) Red line: Growth rate of a crop in isolation that defines the physiological optimum of Env1 under the optimized Env2.

(b) Red line: Example of actual monoculture productivity of the crop that controlled Env1 but not Env2.

(c) Blue line: Ecological optimum of the same crop with symbiotic gain in a mixed community with other plant species that did not affect Env2.

(d) Blue line: Ecological optimum of the crop with symbiotic gain in a mixed community with other plant species, which ameliorated the Env2 condition such as by changing microclimate and soil quality.

Extended Data Figure 2. Mean species diversity in daily observed sections vs. monthly meteorological mean and variance during the second year of synecoculture introduction in the temperate zone (Oiso, Japan). This is the complete data on which Fig 3 (b) in the main text is based. Results for six out of eight 
parameters that showed statistically significant positive correlations between species are shown according to the classification of plant species. No significant positive correlation was observed between the mean and standard deviation of each meteorological parameter. Black solid line: linear regression with less than 5\% significance; dashed line: linear regression with 95\% confidence; dotted line: linear regression with prediction intervals.

\section{Extended Data Figure 3. Product diversity vs. meteorological mean and variance} of synecoculture commercial production in the temperate zone (Ise, Japan). This is the complete data on which Fig 4 (c) in the main text is based. Results of seven out of eight parameters that showed statistically significant positive correlations between the product diversity versus meteorological variance (standard deviation), and not the mean values, are shown. Although significant positive and negative correlations exist between the mean and standard deviation of the meteorological parameters, only the standard deviation showed significant positive correlations with the diversity of products. Black solid line: linear regression with less than 5\% significance; dashed line: linear regression with 95\% confidence; dotted line: linear regression with prediction intervals.

Extended Data Figure 4. Product diversity vs. meteorological mean and variance of synecoculture commercial production in the semi-arid tropical zone (Mahadaga, Burkina Faso). This is the complete data on which Fig 5 (c) in the main text is based. Results of nine out of 19 parameters that showed statistically significant positive correlations between the product diversity and meteorological variance (standard deviation) are shown. Only the standard deviation of downward longwave radiation exclusively correlated with product diversity (shaded in grey), while the other correlations can be alternatively explained as combinations of the correlations between the mean value of a meteorological parameter and product diversity and the correlation between the mean value and standard deviation of a meteorological parameter.

Extended Data Figure 5. Pareto distribution fitting of the species- and sectionwise surface of the experimental plot in Oiso and the crop-wise productivity of the Ise and Mahadaga farms.

The fitted parameters $a$ and $b$ of the Pareto distribution are shown in the legends. Note that the estimated values of $b$ are inferior to the minimum of the $\mathrm{x}$-axis ranges used for fitting, and the values $a>1$ correspond to a Pareto distribution with finite mean value $\mathrm{e}^{30}$. The data are rug-plotted with the same color as the fitting on the bottom and top horizontal axes.

Top: Probability density of species-wise surface percentage data for 80 2-sq.m sections in Oiso (dotted lines with colors according to the classification of plant species in the legend) [Supplementary Data 1]. The 2-sq.m section corresponds to the human scale for manual harvests in the other production experiments (middle and bottom). Double-logarithmic fitting with a Pareto distribution is plotted as solid lines with the same color.

Middle: Probability density of crop-wise daily sales data of the delivery box from the 
Ise farm (black solid line) [Supplementary Data 2]. Double-logarithmic fitting with a Pareto distribution is plotted as a red solid line.

Bottom: Probability density of the crop-wise daily sales data of the Mahadaga farm (black solid line) [Supplementary Data 5]. Double-logarithmic fitting with a Pareto

\section{Extended Data Figure 6. Cost-benefit analysis of Ise and Mahadaga farms.}

993 (a1) Monthly aggregated number of synecoculture produce types sold by the Ise farm (1,000 sq.m) plotted with respect to the monthly gross profit (green circles) [Supplementary Data 2] [Supplementary Data 3] and cost (red circles) in JPY [Supplementary Data 4]. The monthly number of produce types is the product diversity measured by the different number of crops listed in Fig 4 (b) and two additional kinds of products (seeds and seedlings, vegetables and fruits) sold on-site. Significant positive correlations between the gross profit and number of produce types are shown by the green solid line. No significant correlation was observed for cost versus produce types number. Monthly averaged gross profit and cost of conventional market gardening on 1,000-sq.m average in Japan 56 are plotted as comparative thresholds with the dashed blue line for gross profit of production for all scales, the dotted cyan line for the cost of production for all scales, the dashed orange line for the gross profit for farms less than $0.5 \mathrm{ha}$, and the dotted magenta line for the cost of production for farms less than 0.5 ha.

(a2) Fluctuation of gross profit (x-axis) versus cumulative cost divided by benefit ratio (y-axis) of the Ise farm synecoculture production on a monthly scale (green circles connected with solid lines in monthly time series) and on a yearly scale (orange circles connected with solid lines in monthly time series). The productivity of yearly scale conventional market farming that covers the experimented period 2010-2014 is depicted as cyan circles connected by solid lines for production on all scales and as magenta circles connected by solid lines for small-scale $(<0.5 \mathrm{ha})$ production. Fluctuation of gross profit refers to the monthly gross profit minus the median of positive (non-zero) monthly gross profit for the green circles (synecoculture), the 12month gross profit minus the median of all 12-month intervals' gross profit for the orange circles (synecoculture), and the yearly gross profit minus the mean of five years 2010-2014 for the cyan and magenta circles (conventional methods). For each trajectory, the initial point (I.P.) and final point (F.P.) are depicted with a cross-marked circle and a filled circle, respectively.

(b1) Monthly aggregated number of synecoculture produce types sold by the Mahadaga farm (500 sq.m) plotted with respect to the monthly gross profit (green circles) [Supplementary Data 5] and cost (red circles) in XOF [Supplementary Data 7]. Data of five alternative farming methods [Supplementary Data 6] are also plotted with different shapes (see the grey shapes in the legend). Significant positive correlations are depicted with solid lines, which are between the gross profit and produce types number of synecoculture (green solid line) and of the five alternative methods in total (orange solid line), and between the cost and produce types number of the five alternative methods in total (magenta solid line). A significant negative correlation is observed between the cost versus produce types number of synecoculture (red solid line). Monthly averaged gross profit and cost of conventional market gardening on 500-sq.m average in Burkina Faso ${ }^{59}$ are plotted as comparative thresholds with the 
dashed blue line for the gross profit and with the dotted cyan line for introduction and water costs (see Methods).

(b2) Fluctuation of gross profit (x-axis) versus cumulative cost divided by benefit ratio (Y-axis) of the Mahadaga farm's synecoculture production on a monthly scale (green circles connected by green solid lines as a monthly time series) and on a yearly scale (orange circles connected by orange solid lines in a monthly time series). The average productivity of the five alternative farming methods [Supplementary Data 6] is also plotted on a yearly scale (magenta circles connected by solid lines in a monthly time series). Fluctuation of gross profit of synecoculture (green and orange circles) conforms to (a2), while that of the average of the five alternative methods (magenta circles) refers to the 12-month gross profit minus the median of all 12 month intervals' gross profit. The cyan lines with end bars represent the variable ranges of the gross profit ( $\mathrm{x}$-axis) and cumulative cost divided by benefit ratio (y-axis) for the $25^{\text {th }}$ and $75^{\text {th }}$ percentiles of conventional productivity (their intersection corresponds to the median value) based on the ten major crops in Burkina Faso (see Methods) $)^{59}$. For each trajectory, the initial point (I.P.) and final point (F.P.) are depicted as in (a2). The event of a bandit attack (B.A.) in November 2016 near the Mahadaga farm is marked as a circle filled in grey; this event triggered a steep decline in the cost/benefit ratio by exacerbating the local security situation and causing loss of market access ${ }^{58}$.

\section{References}

61. Bogie, N. A. et al. Hydraulic redistribution by native sahelian shrubs bioirrigation to resist in-season drought. Front. Environ. Sci. 6, 98 (2018). 


\section{Figures}

(a) Unimodal Physiological Niche
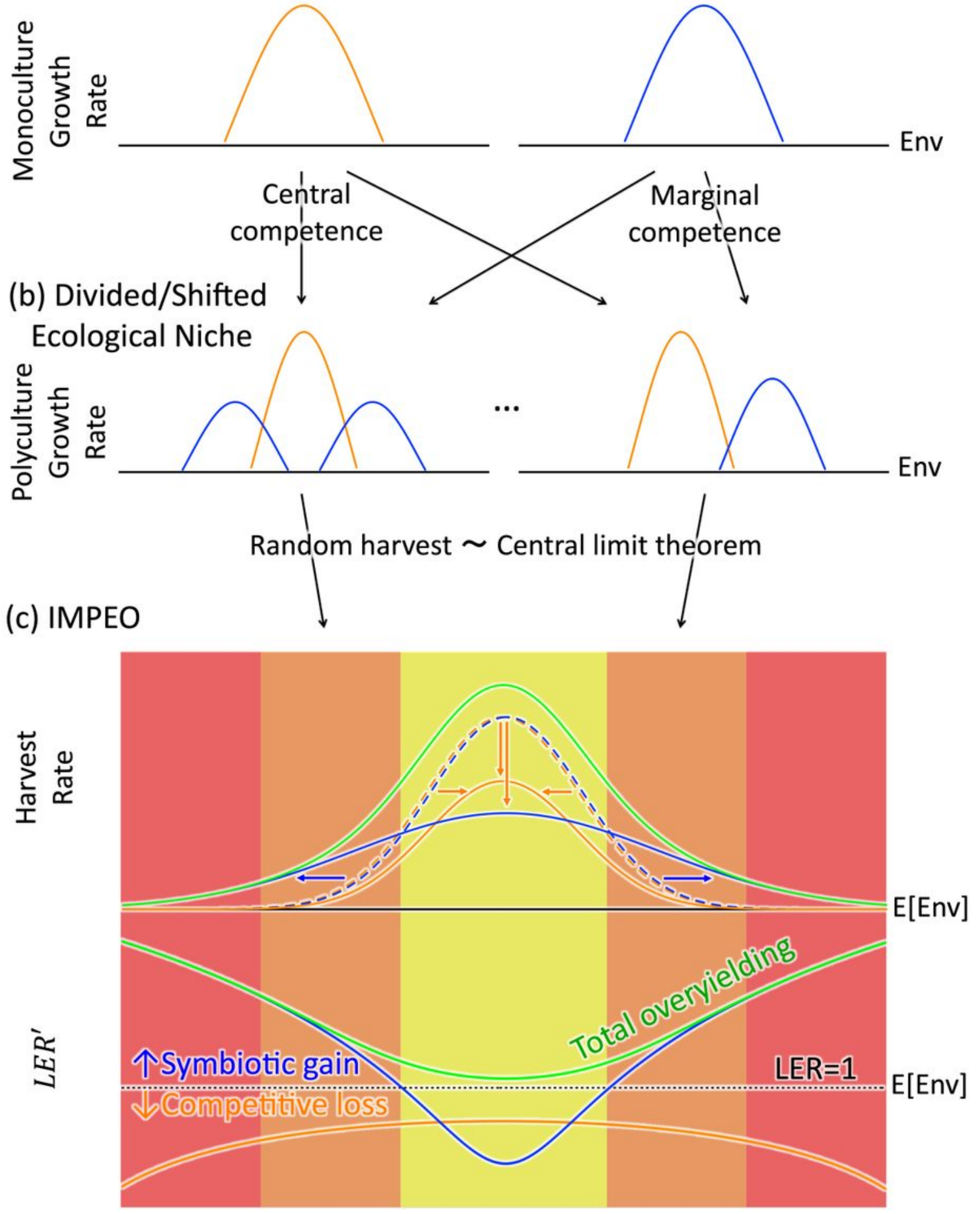

\section{Figure 1}

Relationship between physiological and ecological optima and the total effect of overyielding. (a) y-axis: examples of physiologically optimum isolated growth rate versus $x$-axis: environmental parameters such as temperature, precipitation, sunlight, etc. (b) y-axis: primary productivity of various ecological niches in 
the same environment (x-axis) but mixed communities. (c) Top: random sampling from various niches in (a) (blue and orange dashed lines) and (b) (blue and orange solid lines) converges to normal distributions via the central limit theorem, their frequencies correspond to mean productivity measures such as harvest rate ( $y$-axis) under averaged environmental conditions ( $x$-axis). The overall productivity (green line) includes the productivities of plants of both growth-rate types. (c) Bottom: Effects of symbiotic gain (blue line and arrows) and competitive loss (orange line and arrows) of plants with marginal and central

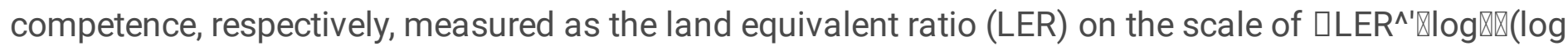

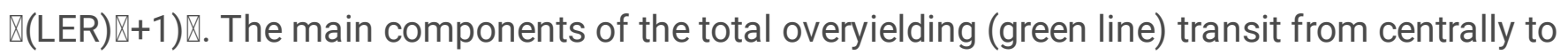
marginally competent species as the environment shifts from the physiological optimum (yellow background) to marginal (orange background) and monoculture intolerant ranges (red background).

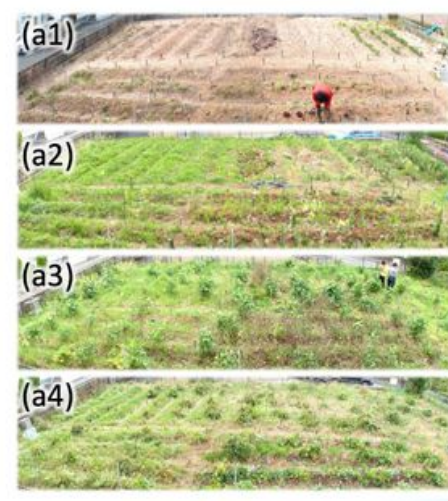

(c1)

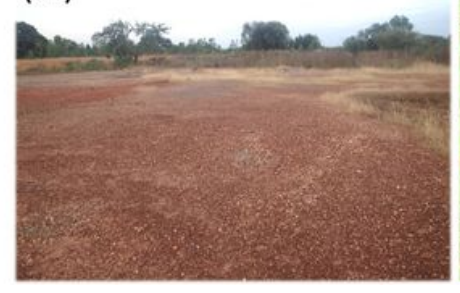

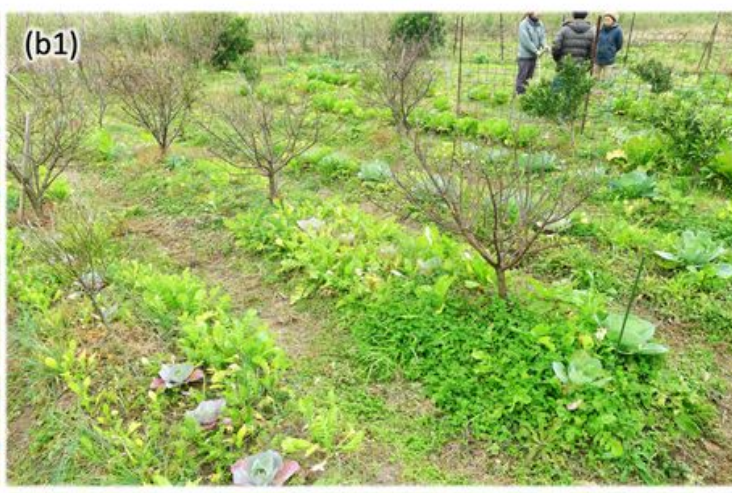
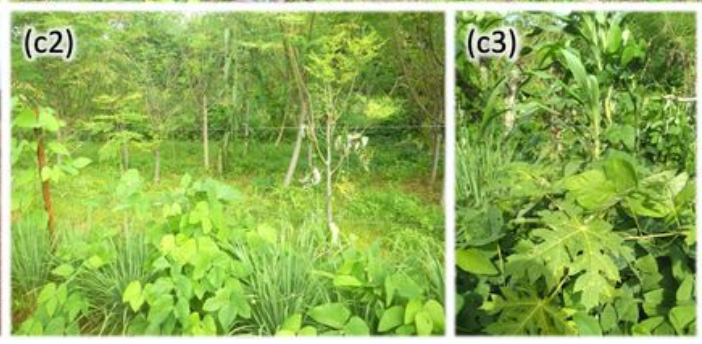

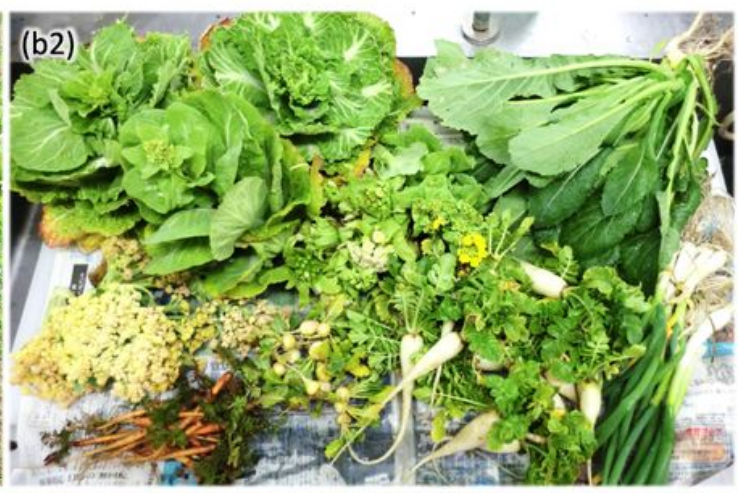

(c4)

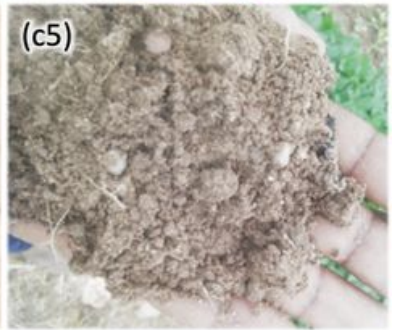

\section{Figure 2}

Synecoculture experimental plots. (a1-a4) Initial vegetation stages during the second year of crop species introduction from bare land in the temperate zone, in Oiso, Japan. After the construction of furrows in January, pictures show the transition of vegetation in (a1) early February, (a2) early May, (a3) late August, and (a4) late October. (b1) Pilot farm production experiment in the temperate zone, in Ise, Japan. Typical mixed polyculture state that augments diversity and productivity of vegetables in November is shown, with (b2) an example of the products packed in a delivery box. (c1-c5) Reversal of the regime shift in the semi-arid tropics, in Mahadaga, Burkina Faso. (c1) The control plot with no intervention remained bare for three years, while (c2) the introduction of 150 edible species established vigorous ecosystems including (c3) a strategic combination of crops with high density and vertical diversity. Partial regeneration of grass is observed in the background of (c1), which appears to be a positive effect from the neighboring synecoculture field (c2-c3). (c4) Little organic matter is visible in the image of the topsoil of the control plot, which is in contrast to (c5) showing the elaborated porous structure in the synecoculture plot. 

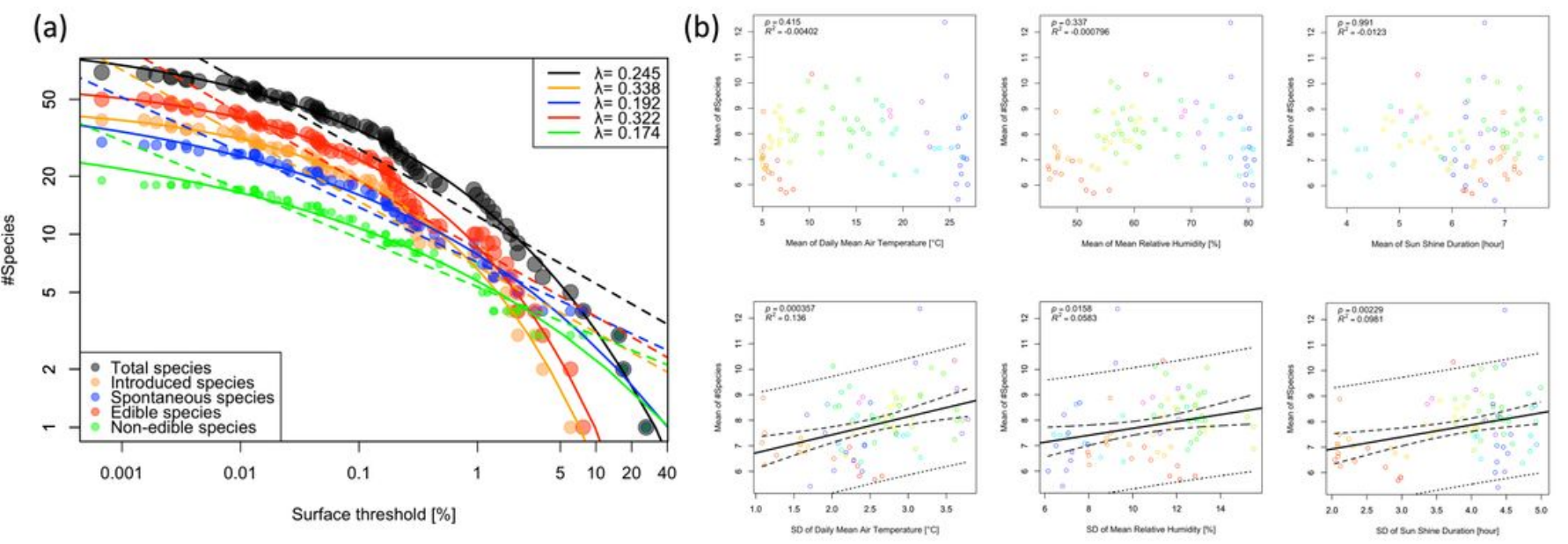

Figure 3

Spatial distribution and positive correlation with environmental variances in the initial stage of ecologically optimum crop growth in the temperate zone. The initial-stage experiment in Oiso, Japan (Fig 2 (a1-a4)) shows that (a) the estimated inverse cumulative distribution of the number of different plant species versus the percentage of the surface they occupy is closer to a power-law distribution that reflects symbiotic interactions $\lambda=0$ than to an exponential distribution that merely reflects competition for resources $\lambda=1$. (b) There exist positive correlations between the mean number of observed species and the variance of meteorological parameters over the 30 days preceding the daily plot observation. There is no observable correlation with the means of the meteorological parameters. Mean plant species diversity versus mean and variance of three meteorological parameters are plotted with circles following the color gradient depicting the date. Black solid line: linear regression with less than $5 \%$ significance; dashed line: linear regression with 95\% confidence; dotted line: linear regression with prediction intervals. 
(a)

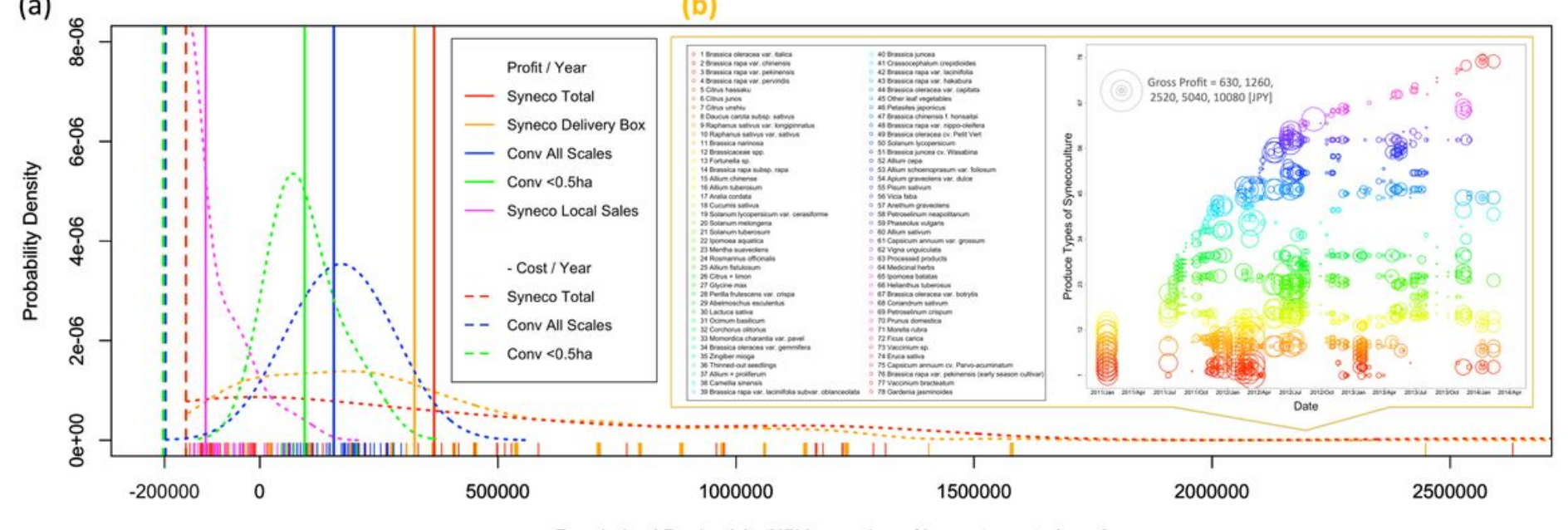

(c)
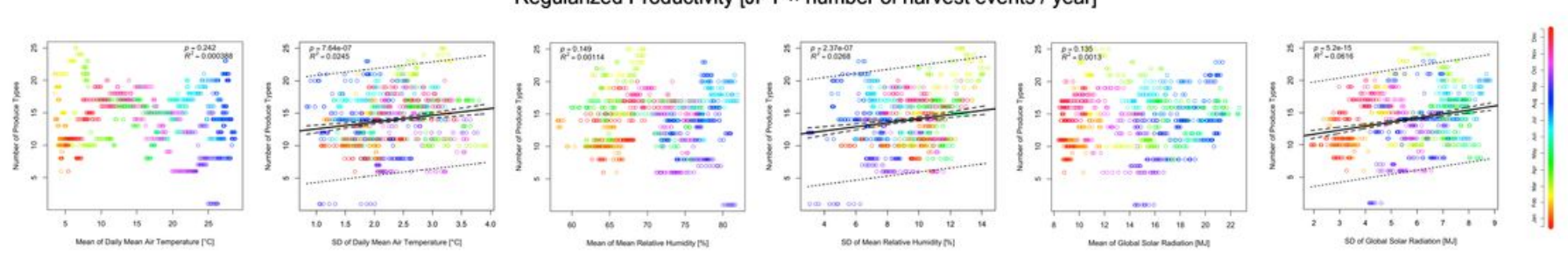

\section{Figure 4}

Productivity of synecoculture experiment in the temperate zone. The four-year production experiment in Ise, Japan shows (a) a power-law distribution of product sales with (b in the orange rectangle) asynchronous harvests of 78 kinds of crop. The $x$-axis of (a) represents sales of each product in synecoculture on 1,000 sq.m (regularized productivity is daily and species-wise productivity in terms of Japanese yen (JPY) multiplied by the number of harvest events per year for synecoculture or yearly reported profit for conventional methods), both with an offset of total costs in order to compare the yearly mean profits (vertical solid lines) and costs (vertical dashed lines) summed as positive and negative values, respectively (see Methods). The dotted lines on the $y$-axis represent the estimated probability distributions for each production category based on the data shown as the rug plots along the x-axis. In (b) left, the 78 academic names of total synecoculture products are shown as a list with a color gradient, and the associated numbers define the value of the y-axis in (b) right, in which the sales for each product according to date on the $\mathrm{x}$-axis is represented as the diameter of the circle with the same color gradient as the list. The correlational analysis in (c) shows significant positive correlations between the number of produce types from synecoculture and meteorological variances for each 30-day interval. There was no significant correlation with the mean of the meteorological parameters. Harvested crop diversity versus mean or variance of three meteorological parameters is plotted as circles following the color gradient of the date. Black solid line: linear regression with less than $5 \%$ significance; dashed line: linear regression with $95 \%$ confidence; dotted line: linear regression with prediction intervals. 


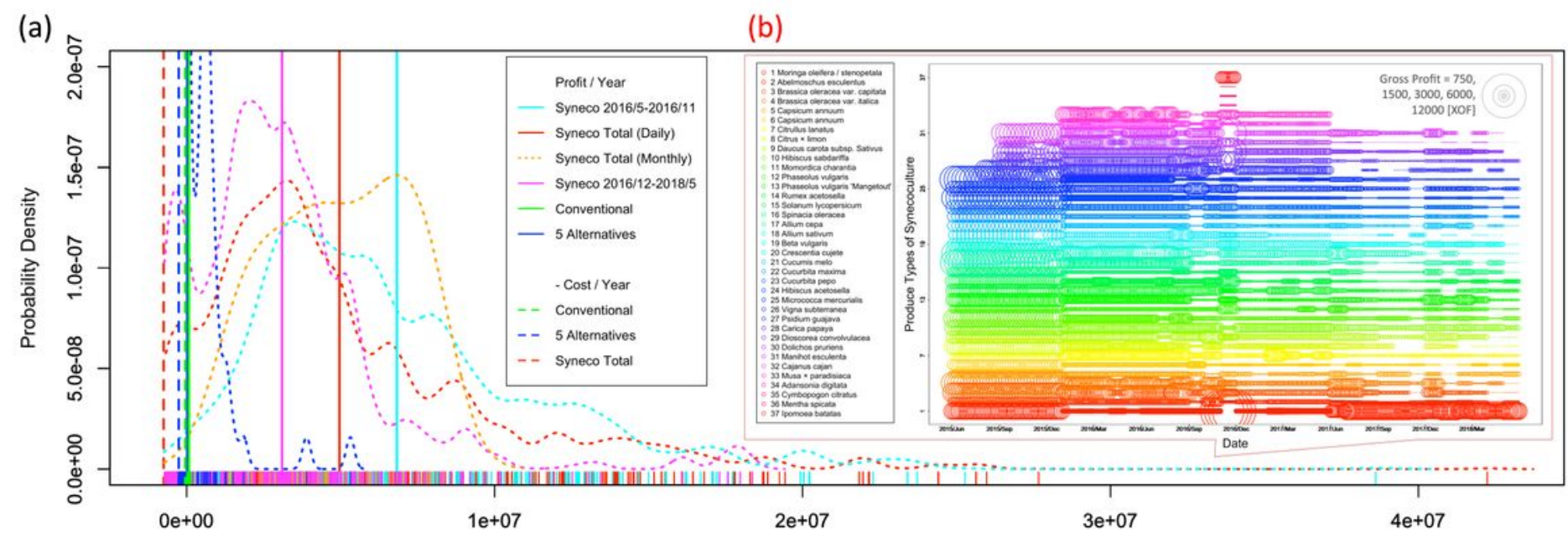

a)

(b)

Regularized Productivity [XOF $\times$ number of harvest events / year]

(c)
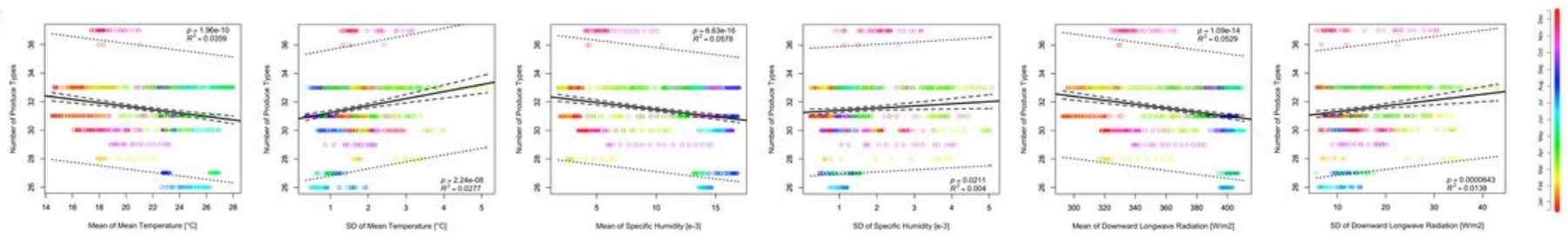

Figure 5

Productivity of synecoculture experiment in the tropical semi-arid zone. The three-year production experiment in Mahadaga, Burkina Faso shows a power-law distribution of product sales with (b in the red rectangle) asynchronous harvests of 37 kinds of crop. The $x$-axis of (a) represents sales of each product for synecoculture and for five alternative farming methods that were simultaneously tested on 500 sq.m (regularized productivity is daily and species-wise productivity in terms of West African CFA franc (XOF) multiplied by the number of harvest events per year for synecoculture and five alternative farming methods or yearly reported profit for the conventional methods), both with an offset of total costs in order to compare the yearly mean profits (vertical solid lines) and costs (vertical dashed lines) summed as positive and negative values, respectively (see Methods). The dotted lines represent the estimated probability distributions for each production category on the y-axis based on the data shown by the rug plots along the x-axis. The total productivity of synecoculture (red line and distribution) is shown on a monthly aggregated scale (orange distribution) and in the two periods before (cyan line and distribution) and after (magenta line and distribution) November 2016, which was the turning point of market accessibility (see Methods). In (b) left, the 37 academic names of total synecoculture products are shown as a list with a color gradient, and the associated numbers define the value of the $y$-axis in (b) right, in which the sales of each product according to date on the $x$-axis is represented as the diameter of the circle with the same color gradient as the list. The correlational analysis in (c) shows significant positive correlations between the number of produce types from synecoculture and meteorological variances for each 14-day interval. There are also significant negative correlations with the means of the meteorological parameters. Harvested crop diversity versus mean or variance of three meteorological 
parameters is plotted as circles following the color gradient of the year's date. Black solid line: linear regression with less than $5 \%$ significance; dashed line: linear regression with $95 \%$ confidence; dotted line: linear regression with prediction intervals.

\section{Supplementary Files}

This is a list of supplementary files associated with this preprint. Click to download.

- SupplementaryData1.csv

- SupplementaryData2.csv

- SupplementaryData3.csv

- SupplementaryData4.csv

- SupplementaryData5.csv

- SupplementaryData6.csv

- SupplementaryData7.csv

- ExtendedDataFigure1.jpg

- ExtendedDataFigure2.jpg

- ExtendedDataFigure3.jpg

- ExtendedDataFigure4.jpg

- ExtendedDataFigure5.jpg

- ExtendedDataFigure6.jpg 